\title{
Vacuum retraction of uterus for the management of atonic postpartum hemorrhage.
}

\author{
${ }^{1}$ Dr Samartha Ram H., ${ }^{2}$ Dr Shankar Ram HS., ${ }^{3}$ Dr Sandhya Ram S., \\ ${ }^{4}$ Dr. Vasudeva Panicker \\ ${ }^{I}$ MBBS.DGO. Consultant obstetrician \& GynecologistSandhya Ram Maternity Hospital,Katampazhipuram, \\ Palakkad, Kerala-India. PIN: 678633 \\ ${ }^{2}$ M.S. (Gen) Sandhya Ram Maternity HospitalKatampazhipuram, Palakkad, Kerala-India. PIN: 678633 \\ ${ }^{3}$ MBBS.DASandhya Ram Maternity HospitalKatampazhipuram, Palakkad, Kerala-India. PIN: 678633. \\ ${ }^{4}$ M.D. (Obgyn)Consultant obstetrician \& Gynecologist.T N Vasudeva Panicker Hospital,11 2nd Main Road, \\ Kodungallur,Thrissure, Kerala- India. PIN: 680664
}

\begin{abstract}
:
Background: Creating negative pressure inside the uterine cavity results in shrinking of uterus which can assist the natural physiological process of contraction and retraction to stop atonic postpartum hemorrhage. Methods: Sixteen women who had normal vaginal delivers, and 4 women who underwent caesarean sections, who developed atonic postpartum hemorrhage, and who did not respond well for routine use of Inj. methergine, oxytocin, and Carboprost were included in this study. A specially designed uterine cannula measuring $25 \mathrm{~cm}$ long and with 12/18mm diameter, with uterine angle, and with multiple perforations on uterine portion was used. When bleeding did not stop due to uterine atony in vaginal deliveries in spite of routine measures, the uterine portion of the cannula was inserted in to uterine cavity up to fundus, and the outer end was connected to suction machine with thick walled flexible tubing. A negative pressure of $650 \mathrm{mmHg}$ was created inside the uterine cavity and maintained for 10mns. This procedure wasrepeated every hour for 3hrs. After this the negative pressure was created whenever there was recurrence of bleeding. In case of caesarean section, the cannula was inserted through the uterine wound and brought outside through vagina. Negative pressure was applied after closure of uterine wound. The cannula was removed in all women6hrs after initiation of procedure. Results: complete cessation of bleeding which was associated with contraction and firm retraction of uterus was observed in all women within 4mns after initiation of procedure. The amount of blood collected in suction bottle ranged from $150 \mathrm{ml}$ to $250 \mathrm{ml}$. Conclusion: Vacuum shrinking of uterus is a very effective physical method which can assist the natural physiological process of contraction and retraction to stop atonic postpartum hemorrhage. This simple, cost effective, life-saving, and fertility saving technique, which can avoid laparotomy can be made available in any setting, and can become the first defense against atonic PPH.
\end{abstract}

Key Words: Vacuum retraction of uterus, Atonic postpartum hemorrhage.

\section{Introduction}

As per the WHO estimate, 287000 maternal deaths occurred globally in the year 2010. Sub-Saharan Africa (56\%) and Southern Asia (29\%) accounted for 245000 maternal deaths (85\%). At the country level, two low resource countries accounted for a third of global burden. India accounted for $56000(19 \%)$ and Nigeria accounted for $40000(14 \%)$ maternal deaths. In India, postpartum hemorrhage was the leading cause of maternal deaths $(29.6 \%)$, and in majority of women atonic PPH was the cause ${ }^{2}$. Many studies reported increasing trends in atonic PPH in recent years ${ }^{3,4}$. Even though some risk factors like obstructed prolonged labor, accidental hemorrhage, and big babies are known to cause atonic PPH, it is not very clear why some women develop atonic PPH and why some women do not ${ }^{5,6}$. For the same reason this problem cannot be predictable'. The only management strategy even today is 'watchful expectancy' and act immediately when the problem develops. Simpler techniques like uterine massage, uterotonics drugs, and uterine packing and balloon tamponadecan be practiced in low resource settings. Techniques like B-Lynch suturing, stepwise devascularization, internal iliac ligation and uterine artery embolization are available at higher medical centers. These higher techniques are not within the reach of every parturient woman when simpler techniques fail. In low resource settings unpredictable sudden massive bleeding makes it difficult to organize competent manpower, compatible blood and transport to higher medical center. Many times mothers die on roads while being transported to higher medical centers due to hypovolemic shock. In some women the speed with which 
the hemorrhage kills the mother is so rapid, that the usually quoted first 1 or 2 hours as "Golden hours" is missing ${ }^{8}$. Sometimes women succumb to death just within 1-1.5 hours after the onset of bleeding ${ }^{8}$. The rapidity with which some women slip in to coagulation failure and multi organ dysfunction syndrome from hemorrhagic shock is alarming. Because of these complex reasons the maternal mortality is not coming down in low resource countries. There is every need for a simpler and sure technique which can stop bleeding, or at least stop bleeding temporarily to buy some time to tide over the crisis. In this study we attempted vacuum constriction of uterus by creating negative pressure inside the uterine cavity with a specially designed uterine cannula, which is a simple, safe and cost effective technique.

\section{Methods}

Sixteen singleton pregnant women who had normal vaginal delivers and 4 women who underwent caesarean sections, and who developed atonic postpartum hemorrhage were included in this study. All the women received 10units of oxytocin IM at the appearance of anterior shoulder, 5 units of intra venous oxytocin after the delivery of placenta, and then uterine massage. Inj. Carboprost $125 \mathrm{micgmsIM}$ was also given when the bleeding did not stop.

Description of uterine vacuum retraction system: Consists of, 1.Uterine retraction cannula. Cannulas are of two different sizes. One measuring $25 \mathrm{~cm}$ long with $12 \mathrm{~mm}$ diameter, and the other one measuring $25 \mathrm{~cm}$ long with $18 \mathrm{~mm}$ diameter, and they have uterine angle and perforations on uterine portion. The perforations on fundal portion are large and longitudinal, and on cervical portion round and small (Fig.1). Smaller perforations were given on cervical portion to prevent blocking of cannula by cervical tissues when suction applied. 2 . Thick walled (not easily collapsible) flexible plastic suction tube with $1.25 \mathrm{~cm}$ diameters. 3. High vacuum suction machine with single bottle, or vacuum extraction pump which can produce negative pressure up to $650 \mathrm{~mm} \mathrm{Hg}$. within $1 \mathrm{mnt}$.

In case of vaginal delivery, when the bleeding did not stop by routine medical measures, under $30 \mathrm{mg}$ pentazocine and $0.6 \mathrm{mg}$ of atropine intravenous analgesia, women were kept in lithotomy position, and the bladder was catheterized with an indwelling catheter. Under good source of light with wide blade vaginal speculum application, the genital tract was explored to exclude traumatic PPH, and to confirm uterine atony. Blood clots were removed from uterine cavity by bimanual compression. The anterior lip of cervix was grasped with sponge holding forceps, and the uterine end of the cannula was inserted in to the uterine cavity up to the level of fundus. Sponge holder and speculum were removed. The outer end of the cannula was connected to the suction machine with suction tube. Air leak in the system was prevented by proper fitting. Theleft palm supporting the fundus on abdomen, right fingers grasp the outer end of the cannula, and push it towards the fundus. Keeping the cannula in this position (to prevent slipping out), suction machine was put on and a negative pressure of $650 \mathrm{mmhg}$ was created and maintained for $10 \mathrm{mnts}$. Then the suction machine was put off. This makes the cannula to get fixed in this position due to sucking of soft cervical tissues in to the perforations.This procedure was repeated every hour for $3 \mathrm{hrs}$. After this, the negative pressure was created whenever there was recurrence of bleeding. Twenty units Pitocin drip in 5\% dextrose 60drops/mint was run throughout the procedure. The cannula was removed after $6 \mathrm{hrs}$ in all women. After the procedure when we tried to pull the cannula, it was not coming out. The temporary adhesions developed due to sucking of soft cervical tissues in to perforations of the cannula were released by gentle finger manipulation. After this the cannula could be easily taken out.

In case of caesarean section the cannula was inserted through the uterine wound and brought outside through vagina. The outer end of the cannula was connected to the suction machine through tubing. The uterine wound was closed quickly. Cannula fixation (tip at the level of fundus) was done in the similar way as mentioned in vaginal insertion and then negative pressure was applied.

Informed and written consent was obtained from all subjects who participated in this study. This study confirms to the standards of declarations of Helsinki.

\section{Results}

Complete cessation of bleeding which was associated with contraction and firm retraction of uterus was observed in all women within $4 \mathrm{mns}$ after initiation of procedure. None of the women had recurrence of bleeding after $3 \mathrm{hrs}$ of initiation of procedure, and there was noneed for repeat suction. All the women were clinically stable during the procedure. The amount of blood collected in suction bottle ranged from $150 \mathrm{ml}$ to $250 \mathrm{ml}$. The clinical details of all women who underwent vacuum constriction of uterus in this study are given Table.1. At caesarean section,we could observe contraction and firm retraction of uterus, and formation of rougosities on the surface of the uterus. 


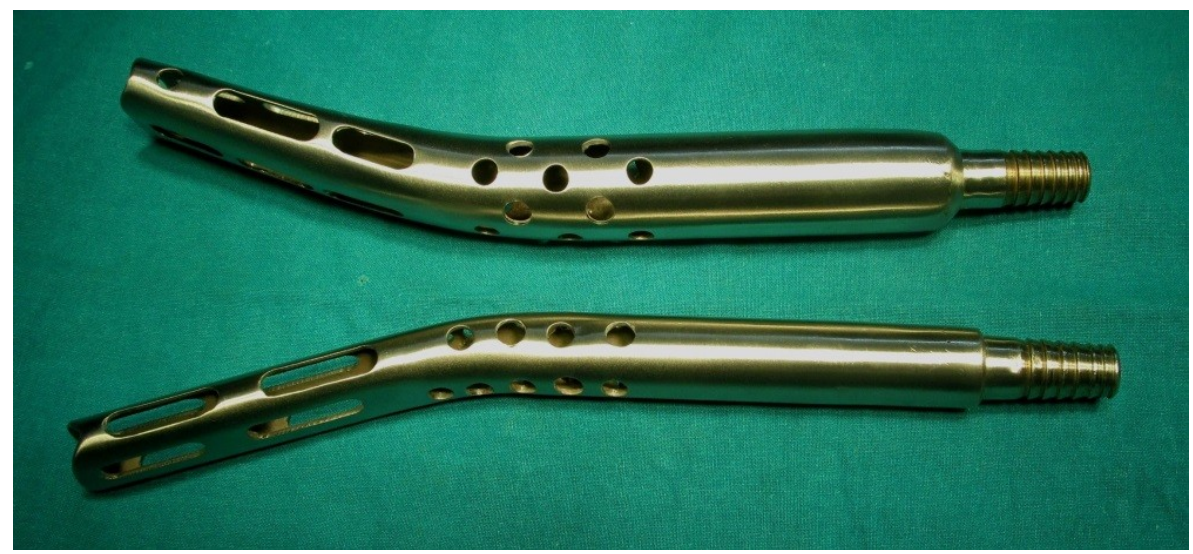

Fig.1 Two uterine vacuum retraction cannulas.One measuring $25 \mathrm{~cm}$ long with $12 \mathrm{~mm}$ diameter, and the other measuring $25 \mathrm{~cm}$ long with $18 \mathrm{~mm}$ diameter, and they have uterine angle and perforations on uterine portion.

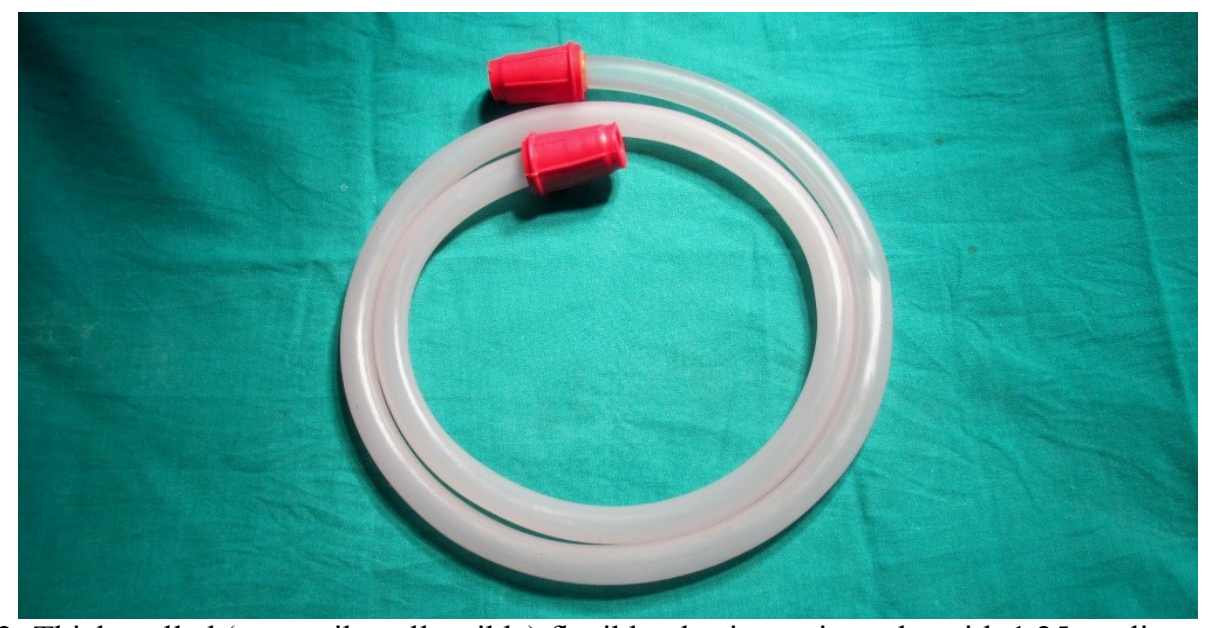

Fig.2: Thick walled (not easily collapsible) flexible plastic suction tube with $1.25 \mathrm{~cm}$ diameters.

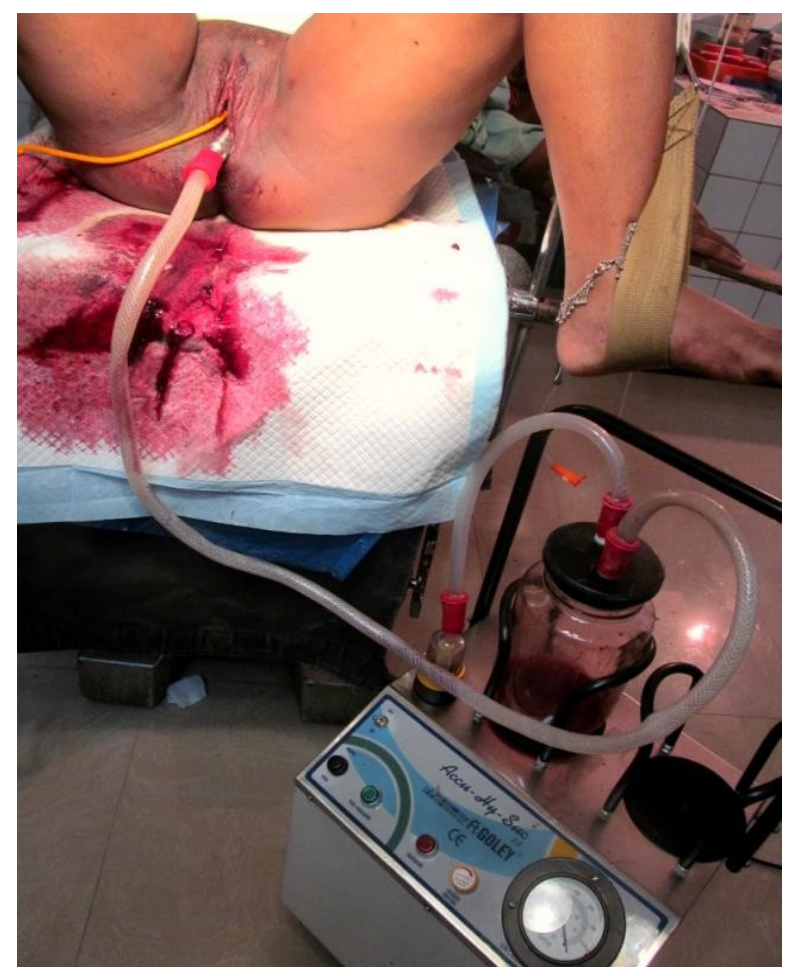

Fig.3: Vacuum retraction of uterus using single bottle suction machine for atonic postpartum hemorrhage. 
Vacuum retraction of uterus for the management of atonic postpartum hemorrhage.

Table1. Clinical details of women who underwent vacuum constriction of uterus for atonic PPH

\begin{tabular}{|c|c|c|c|c|c|c|c|c|}
\hline Case & $\begin{array}{c}\text { Age } \\
\text { (years) }\end{array}$ & Gravida & Para & $\begin{array}{c}\text { Gestation } \\
\text { (weeks) }\end{array}$ & $\begin{array}{c}\text { Duration } \\
\text { of labor } \\
\text { (hrs) }\end{array}$ & $\begin{array}{c}\text { Time taken to } \\
\text { stop bleeding } \\
\text { (mints) }\end{array}$ & $\begin{array}{c}\text { Blood } \\
\text { collected } \\
\text { in bottle } \\
(\mathrm{ml})\end{array}$ & $\begin{array}{c}\text { Mode } \\
\text { of } \\
\text { delivery }\end{array}$ \\
\hline 1 & 32 & 2 & 1 & 39 & 8 & 3.00 & 200 & vaginal \\
\hline 2 & 28 & 3 & 1 & 37 & 6 & 3.50 & 150 & vaginal \\
\hline 3 & 27 & 2 & 1 & 40 & 7 & 3.00 & 250 & vaginal \\
\hline 4 & 29 & 3 & 2 & 40 & 5 & 2.50 & 150 & vaginal \\
\hline 5 & 19 & 1 & 0 & 38 & 11 & 4.00 & 250 & vaginal \\
\hline 6 & 26 & 2 & 2 & 37 & 6 & 3.50 & 200 & vaginal \\
\hline 7 & 30 & 4 & 1 & 39 & 7 & 2.50 & 150 & vaginal \\
\hline 8 & 31 & 2 & 1 & 36 & 8 & 3.00 & 200 & vaginal \\
\hline 9 & 27 & 2 & 1 & 39 & 7 & 3.50 & 200 & vaginal \\
\hline 10 & 26 & 2 & 1 & 38 & 9 & 2.50 & 100 & vaginal \\
\hline 11 & 33 & 3 & 2 & 37 & 5 & 4.00 & 250 & vaginal \\
\hline 12 & 22 & 2 & 1 & 35 & 7 & 3.00 & 200 & vaginal \\
\hline 13 & 29 & 2 & 1 & 36 & 7 & 2.50 & 100 & vaginal \\
\hline 14 & 24 & 2 & 1 & 40 & 6 & 3.50 & 150 & vaginal \\
\hline 15 & 28 & 3 & 2 & 39 & 6 & 3.00 & 150 & vaginal \\
\hline 16 & 32 & 3 & 2 & 36 & 7 & 3.50 & 200 & vaginal \\
\hline 17 & 27 & 3 & 2 & 17 & 0 & 4.00 & 250 & C.S \\
\hline 18 & 31 & 3 & 2 & 35 & 9 & 2.50 & 200 & C.S \\
\hline 19 & 28 & 3 & 2 & 36 & 0 & 3.00 & 200 & C.S \\
\hline 20 & 22 & 1 & 0 & 38 & 12 & 4.00 & 200 & C.S \\
\hline
\end{tabular}

\section{Discussion}

Atonic postpartum hemorrhage is the leading cause for maternal death, especially in developing world $^{1}$. It is the rapid exsanguination of the woman due to uterine atony in a low resource setting makes it difficult to organize competent manpower and compatible blood and transport to save the mother. As the techniques available to control bleeding in low resource settings are inadequate, majority of maternal deaths still continue to occur in theses settings.

In our present study, vacuum retraction could stop bleeding in all 20 women within 4 mnts after the initiation of negative pressure inside the uterine cavity.

Currently the balloon tamponade is being widely advocated as an affordable alternative to blood loss management in severe atonic postpartum hemorrhage refractory to uterotonic therapy ${ }^{9}$. In this technique the uterine cavity is filled with condom balloon or Bakri balloon, and maintained with hydrostatic pressure. This water filled balloon expands the uterine cavity and applies constant pressure (more than the systolic blood pressure) on sinusoids and stops bleeding ${ }^{10}$. The draw backs with this technique include, the mechanism of action is against the natural physiological mechanism of contraction and retraction. It requires some time to organize this balloon tamponade system and to perform tamponade test. This technique cannot be used when tamponade test is negative ${ }^{\mathbf{1 0}}$. When the woman is bleeding profusely, even this few minutes time is very precious and critical. In a case of profuse bleeding due to adherent cotyledons or concealed partial uterine rupture, delay in organizing tamponade system may result in a catastrophe. Sometimes the balloon may get expelled when the tone in the uterine wall increases if the vagina is not effectively packed with gauge ${ }^{\mathbf{1 0}}$. This technique is preferably done in a theater setting after examination under anesthesia to exclude lacerations and retained placenta.

In contrast the mechanisms involved in vacuum retraction include, the negative pressure created inside the uterine cavity results in physical constriction of uterus, and assists the natural physiological process of contraction and retraction. The soft cervical tissues around the cervical portion of the uterine cannula get sucked in to the perforationsresulting in closed uterine cavity. Further application of suction results in quick development of negative pressure inside the uterine cavity resulting in uniform constriction of uterus. This assists the natural physiological process of contraction and retraction and results in cessation of both arterial bleeding and venous oozing. As the negative pressure inside the uterine cavity is maintained in between suctions, the uterus cannot relax and let loose the blood. As the blood circulation to uterus is not interfered, the utero tonic drugs continue to act and maintain the process of contraction and retraction. In this technique blood collected in the uterine cavity get sucked and collected in to the suction bottle and helps to measure the blood loss correctly. As this procedure needs little time and minimal skills, this procedure can be done in labor room settings as a first aid measure. As this is a simple technique, even maternity nurses can be trained, and the 
bleeding can be stopped without any delay. This life saving technique avoids laparotomy and other complex procedures to stop atonic bleeding, and helps to save the mother and her fertility function in low resource settings.

As the soft cervical tissues get sucked in to the perforations of the cannula and become adherent, the uterine cannula cannot be removed easily after the completion of the procedure. Cannula can be removed easily after gentle separation of these adhesions with finger manipulation.

\section{Conclusions}

Vacuum retraction of uterus assists the normal physiological process of contraction and retraction. This simple and cost effective technique, takes very little time to organize and can stop bleeding with in 4mnts in atonic PPH as shown in this study. This lifesaving technique is useful in all settings especially in low resource settings. Vacuum retraction cannula should be made part and parcel of normal delivery tray, and the labor room staff should be trained in this technique, so that bleeding can be stopped without any delay. We anticipate wider applications for this technique in the management of placenta praevia, placenta accreta percreta, and traumatic PPH with some modifications. Its utilization in cases of inherited coagulopathies of pregnancy and DIC has to be further explored. The long term effects of ischemia on cervix and uterus due to vacuum effect has to be further explored. As this is a small study, these results have to be further evaluated by randomized controlled studies with larger sample size before its recommendation for general use.

\section{References}

[1]. Trends in maternal mortality: 1990 to 2010, WHO, UNICEF, UNFPA and The World Bank estimate Executive summary, Page no 1

[2]. A Text book of postpartum hemorrhage Edited by Christopher B-Lynch, Louis G. Keith MD. Chapter 49, Combating postpartum hemorrhage in India- moving forward. Page 434.

[3]. Lutomski JE, Byrne BM, Devane D, Greene RA. Increasing trends in atonic postpartum haemorrhage in Ireland: an 11-year population-based cohort study. BJOG. 2012 Feb; 119(3):306-14.

[4]. Callaghan WM, Kuklina EV, Berg CJ. Trends in postpartum hemorrhage: United States, 1994-2006. Am J ObstetGynecol 2010; 202:353.e1.

[5]. WHY MOTHERS DIE, KERALA - 2006-09: Editors: VP Paily, K Ambujam, Betsy Thomas Observations, recommendations: Second Report of Confidential Review of Maternal Deaths: Page 71.

[6]. Dwight J. Rouse, MD, MSPH, Sharon Leindecker, MS, MBA et al. The MFMU Cesarean Registry: Uterine atony after primary cesarean delivery: AJOG. 2005 sept; Volume 193, Issue 3, Supplement, Pages 1056-1060.

[7]. A Comprehensive Textbook of Postpartum hemorrhage. 2nd Edition. Edited by Sir SabaratnamArulkumaran, MahanteshKaroshi. Chapter37: Preparedness for Postpartum Hemorrhage: an Obstetric Hemorrhage Equipment Tray: Page 314.

[8]. Why Mothers Die, Kerala - 2004-05: First Report of Confidential Review of Maternal Deaths: Edited by V P Paily, 2009. Pages 41, 61,60

[9]. John W. Snelgrove, MD, Postpartum Haemorrhage in the Developing World: A Review of Clinical Management Strategies, Mcgill J Med. 2009; 12(2): 61 .

[10]. A Text book of postpartum hemorrhage Edited by Christopher B-Lynch, Louis G. Keith MD. Chapter 29, THE BALLOON INTERNAL UTERINE TAMPONADE AS A DIAGNOSTIC TEST by S. Ferrazzani, L. Guariglia and C. Dell'Aquila Page 269 and 271 